\title{
A METROPOLIZAÇÃO DA CRIMINALIDADE COM A TERRITORIALIZAÇÃO DAS UPPS: DA MIGRAÇÃO A EXPANSÃO
}

\author{
Metropolisation crime with the territorialization UPPs: \\ The expansion of migration
}

\section{Crimen con metropolización la territorialización UPPs: La expansion de la migración}

\author{
Graciano Lourenço Fernandes Junior \\ Mestre em Dinâmica dos Oceanos e da Terra - DOT - UFF \\ gracianolourenco@ibest.com.br
}

Artigo recebido em 25/05/2015 e aceito para publicação em 03/02/2016

DOI: $10.12957 /$ tamoios.2016.16484

Resumo Este trabalho é uma análise sobre aos desdobramentos da política de (in) segurança e seus impactos na cidade do Rio de Janeiro, articulando em especifico, os mecanismos de controle na produção do projeto de cidade e sua problemática. A chamada política de (in) segurança pública do Rio de Janeiro, em verdade, se materializa numa política de planejamento da cidade que, cada vez mais, apresenta um quadro de aprofundamento dos processos de ampliação dos espaços de segregação. Este processo é resultado de uma fragmentação do tecido "sócio-espacial" que favorece ao capital imobiliário na acumulação capitalista e o uso do solo de forma favorável. Neste sentido, as chamadas UPPs junto com outros instrumentos de gestão urbana, têm provocado algumas transformações importantes na cidade: como a metropolização da criminalidade com a territorialização das UPPs, numa dinâmica de migração e de expansão territorial.

Palavras-chaves: Rio de Janeiro (município); Projeto de cidade; UPPs. Migração; Segregação sócio-espacial

Abstract This work is an analysis of the unfolding of the (in) security and its impact on the city of Rio de Janeiro policy in articulating specific, mechanisms controlling the production of the draft city and its problems. The so-called policy of public (in) security of Rio de Janeiro, in fact, is materialized in a city that increasingly presents a framework for deepening the processes of segregation widen its planning policy. This process is a result of fragmentation of the "socio-spatial" fabric that favors the real estate capital in capitalist accumulation and land use favorably. In this sense, the UPP calls along with other urban management instruments have caused some major changes in the city: as the metropolis of crime with the territorialisation of UPP, a dynamic migration and territorial expansion.

Keywords: Rio de Janeiro (city); City Project; UPP; Migration; Socio-spatial segregation.

Resumen Este trabajo es un análisis del desarrollo de la (in) seguridad y su impacto en la ciudad de la política de Rio de Janeiro en la articulación de mecanismos específicos, el control de la elaboración del proyecto de la ciudad y sus problemas. La llamada política de (in) seguridad pública de Río de Janeiro, de hecho, se materializa en una ciudad que se presenta cada vez más un marco para la profundización de los procesos de segregación ampliar su política de planificación. Este proceso es el resultado de la fragmentación de la tela "socio-espacial" que favorece el capital inmobiliario en la acumulación y uso del suelo capitalista favorablemente. En este sentido, la UPP llama junto con otros instrumentos de gestión urbana, han provocado algunos cambios importantes en la ciudad: como la metrópoli de la delincuencia con la territorialización de las UPP, una migración dinámica y expansión territorial.

Palabras clave: Río de Janeiro (ciudad); Proyecto de la Ciudad; UPP; Migración. La segregación socio-espacial. 


\section{INTRODUÇÃO}

Este artigo é resultado do desdobramento de algumas ideias apresentadas ao Curso de Pós-Graduação Latu Sensu de Dinâmicas Urbanas Ambientais e Gestão do Território da Faculdade de Formação de Professores da Universidade do Estado do Rio de Janeiro (FFP/UERJ) - Departamento de Geografia como requisito para obtenção do grau de Especialista em Geografia, intitulado Unidade de Polícia Pacificadora (UPP) na era dos Mega Eventos: Algumas reflexões sobre a política de segurança pública na cidade do Rio de Janeiro, pós Pan-Americano de 2007 (FERNANDES JUNIOR, 2012).

Nesta ótica o debate sobre a implementação das Unidades de Polícia Pacificadora (UPPs) nos remete a natureza da relação entre Estado e Sociedade no que tange seus graus e formas de intervenções no espaço pelo modelo de (In) Segurança Pública (HAESBAERT, 2010)1, onde o processo de deslocamento da criminalidade, segue um desdobramento lógico, onde os criminosos migram das áreas territorializadas pela implementação das UPPs para outras regiões mais próximas comandadas pela mesma facção criminosa e até mesmo ultrapassam este nível de abrangência numa escala de metropolização da criminalidade, numa dinâmica de migração e de expansão territorial.

Desta forma o objetivo de pesquisa foi à análise da metropolização da criminalidade com a territorialização das UPPs, numa dinâmica de migração e de expansão territorial.

Iniciamos nossa metodologia com o mapeamento das UPPs referente às suas localizações, a fim de entendermos como ocorre o seu funcionamento e suas práticas espaciais (CORREA, 1992) e, subsequentemente, qual é a sua geoestratégia² (VESENTINI, 2011) de uso e controle do espaço da cidade. Além de correlacionar estes posicionamentos com grupos de criminosos, e modificações estruturais do espaço urbano carioca através de seu reordenamento. Para tal, analisamos reportagens de jornais, dados do Departamento Geral de Tecnologia da Informação e Telecomunicações (DGTIT), dados da Polícia Civil do Estado do Rio de Janeiro (PCRJ), dados da Secretaria de Segurança Pública (SESEG), dados do Instituto de Segurança Pública (ISP), dados da coordenação das Unidades de Polícia Pacificadora - UPPs para elaborarmos mapas e gráficos. 


\section{ALGUMAS CONSIDERAÇÕES SOBRE OS IMPACTOS DA POLÍTICA DE (IN) SEGURANÇA NA CIDADE DO RIO DE JANEIRO}

Entendemos que o modelo de intervenção seletivo e pontual inserido no espaço urbano carioca pelo poder público ${ }^{3}$ através da segurança pública tem gerado vertentes, como a metropolização da criminalidade com a territorialização das UPPs, numa dinâmica de migração e de expansão territorial. Deixando claro que a utilização do conceito de metropolização, será empregado apenas num sentido de escala, pois a violência urbana se espacializa nas metrópoles ao mesmo tempo em que se recria territórios para a sua atuação.

Nesta dinâmica, é importante ressaltar que a territorialização da criminalidade ligada às "Organizações Criminosas" nas favelas ou periferias se caracteriza pelo fato de submeter à população a lógica da violência urbana através de forte controle e repressão pelos agentes ligados ao crime organizado passando a estabelecer regras que garantam o domínio sobre o território (HAESBAERT, 2007). Estamos diante de novas formas e novos conteúdos da violência e da criminalidade moderna, devido à nova territorialização implementada pelas UPPs através de suas intervenções geoestratégicas em áreas dominadas pela "estética do poder" de grupos de narcotraficantes (FERNANDES JUNIOR, 2012).

Entendemos que está ocorrendo uma mudança na base de poder sobre determinadas áreas, agora "controladas" pelas UPPs. Neste sentido, o Estado regula e institui uma nova ordem de conduta e territorialidade, modificando de certa forma as ações táticas e estratégicas dos grupos de narcotraficantes e ao mesmo tempo, impondo suas práticas espaciais de controle sócioespacial numa nova territorialização.

Os grupos de narcotraficantes impedidos de impor sua territorialidade e sua "estética do poder" nas áreas ocupadas pelas UPPs recriam territórios para sua atuação numa nova territorialização para além da escala local, materializadas no que chamaremos de metropolização da criminalidade (FERNANDES JUNIOR, 2012).

De acordo com o artigo publicado no Terra Online (2010), o Secretário Estadual de Segurança, José Mariano Beltrame, admitiu que os narcotraficantes das favelas Cidade de Deus (também chamada de CDD por seus moradores, é um bairro desmembrado de Jacarepaguá oriundo de um conjunto habitacional situado na Zona Oeste da cidade do Rio de Janeiro), Pavão-Pavãozinho (situado na fronteira entre os bairros de Ipanema e 
Copacabana, na Zona Sul da Cidade do Rio de Janeiro), Santa Marta (localizada no Morro Santa Marta entre os bairros de Santa Teresa e Botafogo mais próximo a zona sul do Rio de Janeiro) e Borel (localizado no bairro da Tijuca, na Zona Norte da cidade) na época pacificadas, refugiaram-se nos Complexos do Alemão e Penha ( apontados pela polícia como "quartel-general" da facção Comando Vermelho (CV), que se tornou na época reduto dos principais "chefões" da facção, especialmente, pela dificuldade de acesso, localizadas na zona norte da cidade.

Entendemos que o deslocamento dos narcotraficantes para outras áreas (da cidade), como por exemplo, os Complexos do Alemão e Penha está diretamente ligado a territorialização das UPPs, onde as facções dos morros que sofreram intervenções com a implementação destas unidades sofreram um enfraquecimento das relações de poder e controle espacial do território, migraram do âmbito local para se reterritorializar em outras localidades.

Segundo o jornal R7 Online (2011), a migração de traficantes dos complexos de favelas do Alemão e da Penha, que funcionavam como "quartel-general" da maior facção criminosa do Estado do Rio de Janeiro, o Comando Vermelho (CV), até novembro de 2010, quando a região foi ocupada pelas forças policiais, juntamente com o Exército pode ser comprovada em números, conforme índices da Delegacia de São Cristóvão (17º DP).

Em consonância com as informações do R7 Online (2011), os índices de crimes como roubos de veículos e a pedestres diminuíram na região do Complexo do Alemão e Penha, no mês de março de 2011, se comparado ao mesmo período, em 2010, em contra partida, houve um aumento dessas ocorrências em locais próximos ao morro da Mangueira, por exemplo, que passou a abrigar grande parte das lideranças que deixaram a "fortaleza da quadrilha"(Complexo do Alemão e Penha), ou seja, exemplificando a ideia de migração dos grupos de narcotraficantes inicialmente para áreas próximas dominadas por grupos da mesma facção criminosas. A circunscrição da Delegacia de São Cristóvão (17 $\mathrm{DP})$, que é responsável pelo Morro da Mangueira, registrou um aumento, por exemplo, nos índices de roubos de veículos que passaram de 15 (quinze) para 27 (vinte e sete) e nos roubos a pedestres que passaram de 93 (noventa e três) para 109 (cento e nove), índice também comparado ao mês de março em 2010 e 2011, de acordo com o Instituto de Segurança Pública (ISP). No total de roubos, que inclui veículos, pedestres, cargas, estabelecimentos comerciais, entre outros, também houve aumento nas áreas da Delegacia de São Cristóvão (17 $\mathrm{DP})$ que passaram de 157 para 197 roubos e da Delegacia do Engenho 
Novo (25 DP), que responde pelo Jacarezinho que passaram de 185 para 190 roubos, de acordo com o Instituto de Segurança Pública (ISP).

Segundo ainda R7 Online (2011), na área da Delegacia de Bonsucesso (21 a DP), os homicídios passaram de 04 (quatro) para 05 (cinco) no mesmo período. Por outro lado, na Delegacia da Penha (22 DP), que atende a casos ocorridos no Complexo da Penha e grande parte do Alemão, os homicídios caíram mais da metade, de 05 (cinco) para 02 (dois), no mesmo período comparativo. Enquanto ao roubo de veículos, a redução também foi grande, passaram de 44 (quarenta e quatro) para 21 (vinte e um), menos da metade. Também houve queda de 50\% nos roubos a pedestres, que passaram de 131 (cento e trinta e um) para 66 (sessenta e seis). Neste contexto, a Mangueira, Jacarezinho e Manguinhos se tornaram na época os principais refúgios para criminosos que escaparam do Alemão e da Penha, de acordo com o Instituto de Segurança Pública (ISP).

Segundo o G1 Online (2012) bandidos estariam migrando dos morros pacificados para região metropolitana, aumentando os assaltos violentos, conforme o próprio Secretário Estadual de Segurança José Mariano Beltrame, em entrevista ao programa jornalístico da TV Bom Dia Brasil confirmou, que com a ocupação da polícia em favelas do Rio de Janeiro, bandidos fugiram e migraram para Niterói e outras áreas próximas como São Gonçalo, Itaboraí e Maricá. Os números mostram que o Município de Niterói os roubos a residências aumentaram mais de 500\%, enquanto roubos a veículos e a lojas cresceram quase $80 \%$. Também houve um aumento de $18 \%$ nos roubos a pedestre na comparação de fevereiro de 2012 com o mesmo mês do ano de 2011, de acordo com dados do Instituto de Segurança Pública (ISP).

Segundo o G1 Online (2012) em função do aumento da violência e do número de assaltos na região de Maricá e Niterói, a Polícia Militar através do $12^{\circ}$ Batalhão que é responsável pelo patrulhamento destes municípios, está querendo criar um cinturão cercando todos os acessos à cidade (medida de controle socioespacial). Segundo dados do Instituto de Segurança Pública (ISP), em fevereiro de 2012 o número de assaltos a estabelecimentos comerciais aumentou 38,4\% com relação ao mesmo período do ano de 2011 passando de 26 (vinte e seis) para 35 (trinta e cinco). Os roubos de residências subiram 285,7\% passando de 7 (sete) para 27 (vinte e sete), os roubos de veículos cresceram 71,1\% passando de 83 (oitenta e três) para 142 (cento e quarenta e dois) e os assaltos a pedestres aumentaram 13,5\% passando de 251 (duzentos e cinquenta e um) para 285 (duzentos e oitenta e cinco). 
Essa também é a realidade de quem mora no extremo da zona oeste, berço das milícias ${ }^{4}$ cariocas. Na região de Santa Cruz e Guaratiba, por exemplo, a taxa de homicídios foi de 43,6 casos por 100 mil habitantes. Nas áreas vizinhas de Bangu e Realengo, campeã das mortes violentas da capital (268 vítimas), a taxa foi de 39,4 casos.

Já em Campo Grande, onde os grupos armados formados por policiais e ex-policiais controlam serviços públicos, como transporte coletivo, a taxa foi de 33,4 homicídios por 100 mil habitantes. Para efeito comparativo, a taxa de mortos na Guerra do Iraque em 2004 foi de 34,9 vítimas, segundo o Global Burden of Armed Violence (2011). No Rio, a taxa é de 27 (vinte e sete) casos por 100 mil habitantes.

Juntas, essas três áreas do subúrbio da zona oeste do Rio somam 1,6 milhão de moradores, $26 \%$ da população carioca (6,3 milhões), assistiram a $37,5 \%$ de todas as mortes violentas registradas na capital (1.715) nos últimos 12 meses.

Segundo UOL Online (2013) dados divulgados pelo ISP (Instituto de Segurança Pública) apontam que o número de homicídios dolosos (quando há intenção de matar) teve aumento 38\% em agosto, em comparação ao mesmo mês do ano de 2012. O levantamento registra 406 (quatrocentos e seis) casos em 2013 antes 294 (duzentos e noventa e quatro) em 2012. Desde junho de 2013, o centro e a zona sul da capital fluminense têm sido palco de protestos que, em sua maioria, terminam em confronto com policiais militares e depredação de agências bancárias, estabelecimentos comerciais e prédios públicos. A região onde o número de homicídios mais aumentou no comparativo entre agosto dos dois anos, no entanto, foi a de Niterói e cidades do entorno: uma variação de 186,7\%, passando de 15 em agosto de 2012 para 43 (quarenta e três) no mesmo período em 2013. 


\section{Figura 1}

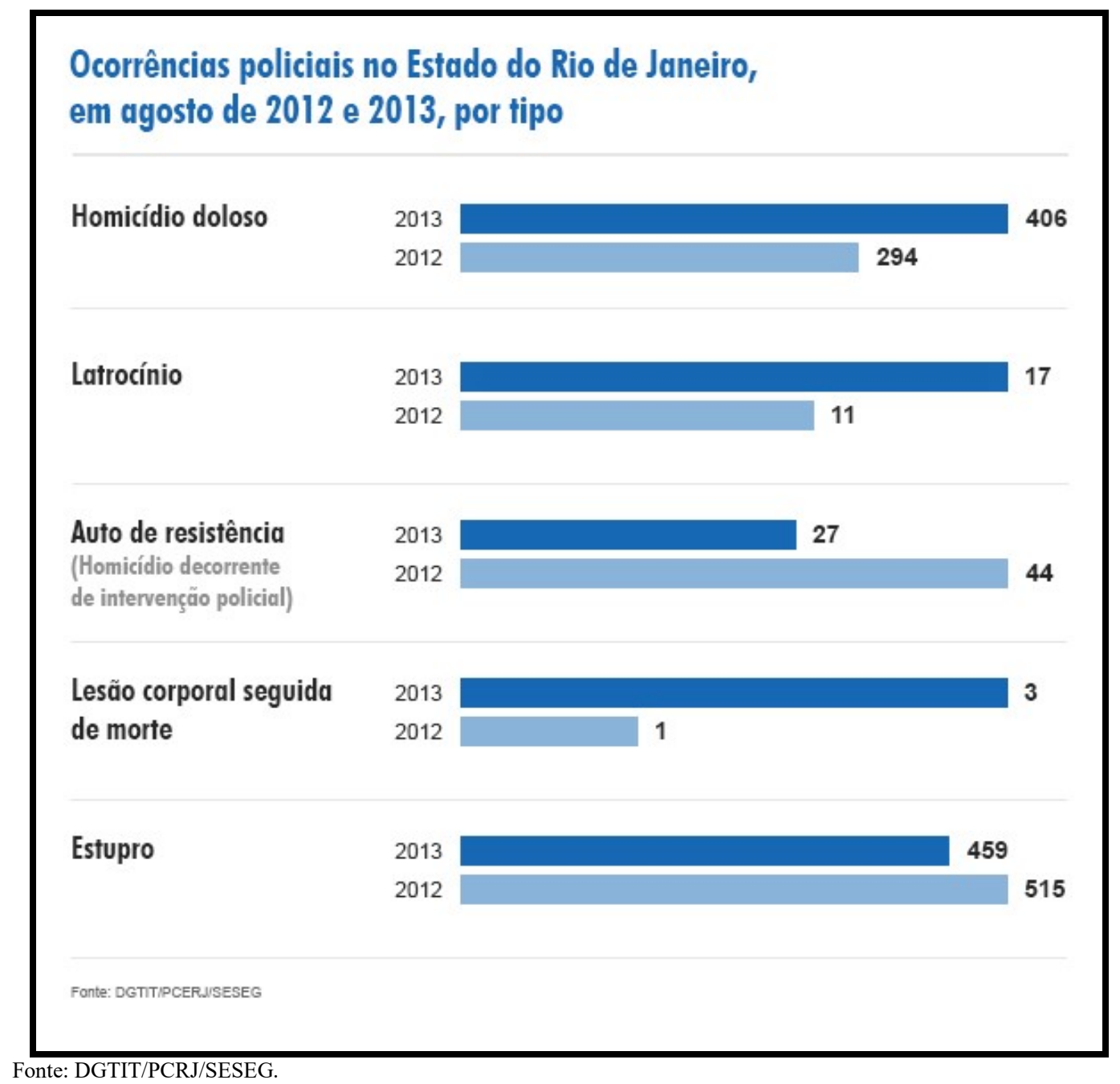

De acordo com UOL Online (2013) a segunda maior variação ocorreu no interior do Estado, com 37,5\%, seguido pela Baixada Fluminense, com um aumento de 34,6\%. Por último, a capital registrou uma variação de $18,9 \%$. O roubo a coletivos foi o crime que apresentou maior aumento no comparativo: de 345 (trezentos e quarenta e cinco) em agosto de 2012 para 629 (seiscentos e vinte e nove) em agosto de 2013 (variação de 82,3\%). 


\section{Figura 2}

\section{Aumento no número de homicídios culposos no Estado do Rio de Janeiro, entre agosto de 2012 e 2013, por regiões}

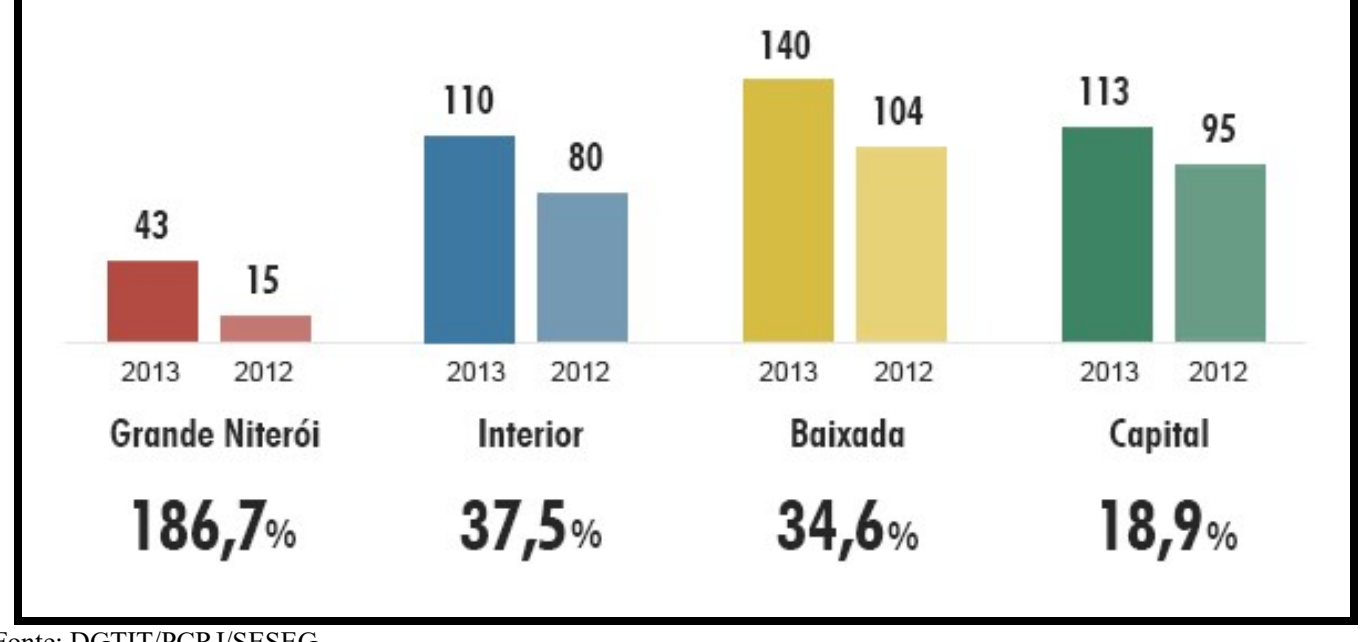

Fonte: DGTIT/PCRJ/SESEG.

O Instituto de Segurança Pública do Rio de Janeiro divulgou os dados de crime e violência referentes ao primeiro trimestre de 2014. Tais dados demonstram o aumento do processo de migração e expansão da criminalidade para outros municípios, especialmente fora da capital.

Neste sentido, o Gráfico 1 mostra a evolução da taxa de homicídios por 100 mil habitantes. A taxa aumentou em $24 \%$ na região metropolitana (sem a capital) e $49 \%$ nos outros municípios do estado entre o primeiro trimestre de 2013 e 2014. O aumento da violência no interior do estado ocorreu, sobretudo, na região do Norte Fluminense. Campos do Goytacazes, Macaé, Cabo Frio, Rio das Ostras e São João da Barra tiveram mais de 50\% de aumento no número de homicídios e respondem juntos por dois terços do aumento de homicídios ocorridos no interior do estado. Na região Metropolitana, Nova Iguaçu, São João de Meriti, Nilópolis e Queimados também tiveram aumentos expressivos, todos de mais de 50\%, e responderam por $75 \%$ do aumento de homicídios da região metropolitana.

O Gráfico 1 mostra ainda que a trajetória de aumento da taxa de homicídios na região metropolitana e no restante do estado começou em 2012 e fez com que essas regiões voltassem a ter índices de violência semelhantes aos do ano de 2007. Por sua vez, na capital do estado a taxa de homicídios ainda é 45\% menor do que era em 2007, a despeito das variações recentes. 


\section{Gráfico 1- Evolução da taxa de homicídios.}

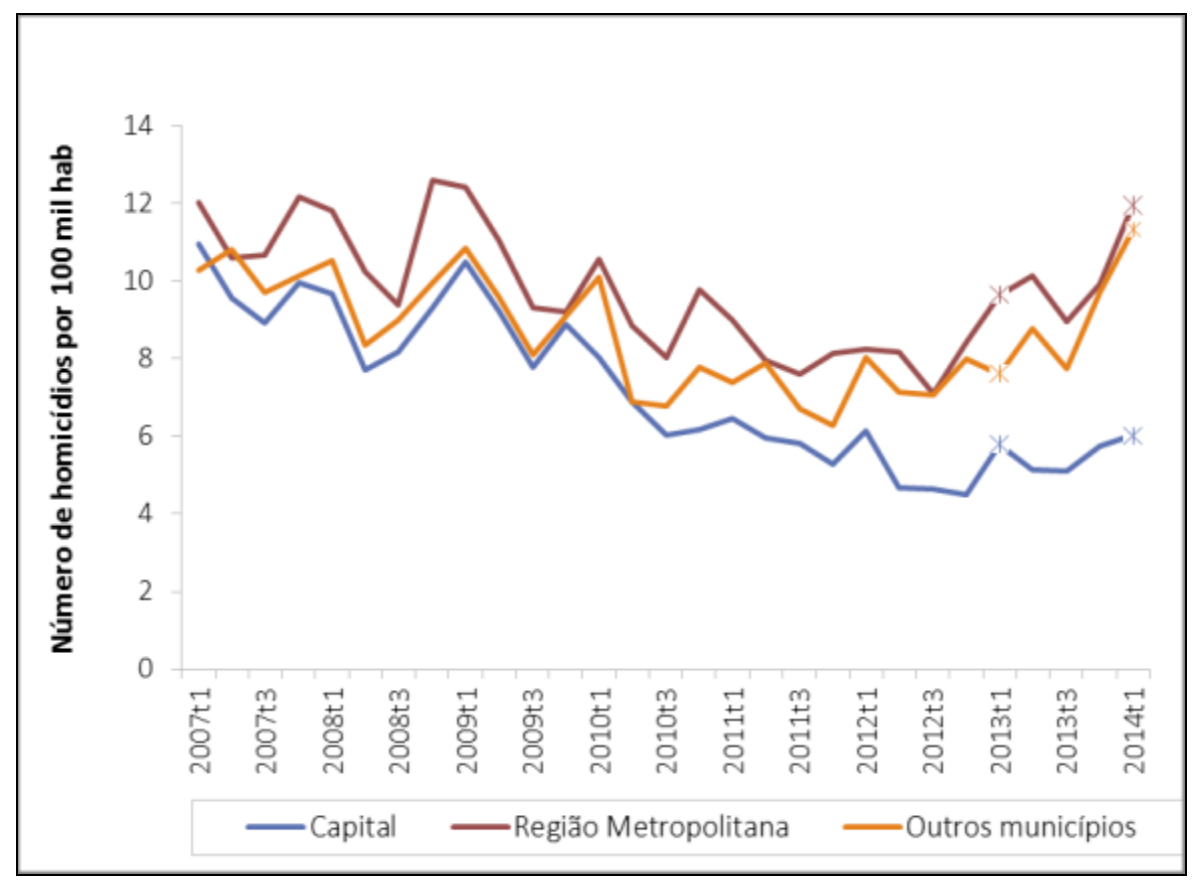

Fonte: Elaboração própria baseada em dados da SESEG.

O Gráfico 2 mostra que houve também um forte aumento na criminalidade a partir de 2013, medida pelo número de registros de crimes ao patrimônio ${ }^{5}$, principalmente na região metropolitana e na capital. No caso da capital, a taxa de crimes ao patrimônio no primeiro trimestre de 2014 foi de 395 (trezentos e noventa e cinco) registros por 100 mil habitantes, que equivale a 25.411 (vinte e cinco mil quatrocentos e onze) ocorrências de roubos e furtos em três meses. Esse valor é equivalente ao que foi registrado em meados de 2009 e indica que todos os ganhos obtidos desde então foram revertidos. No caso da região metropolitana, a situação é ainda mais grave. A taxa de crimes ao patrimônio começou a subir mais fortemente em 2012 e hoje é 67\% maior do que era em 2007. Estes fatos intensificaram a fragmentação do tecido sóciopolitico da cidade do Rio de Janeiro e da região metropolitana (SOUZA, 1998). 


\section{Gráfico 2 - Evolução da taxa de crimes ao patrimônio}

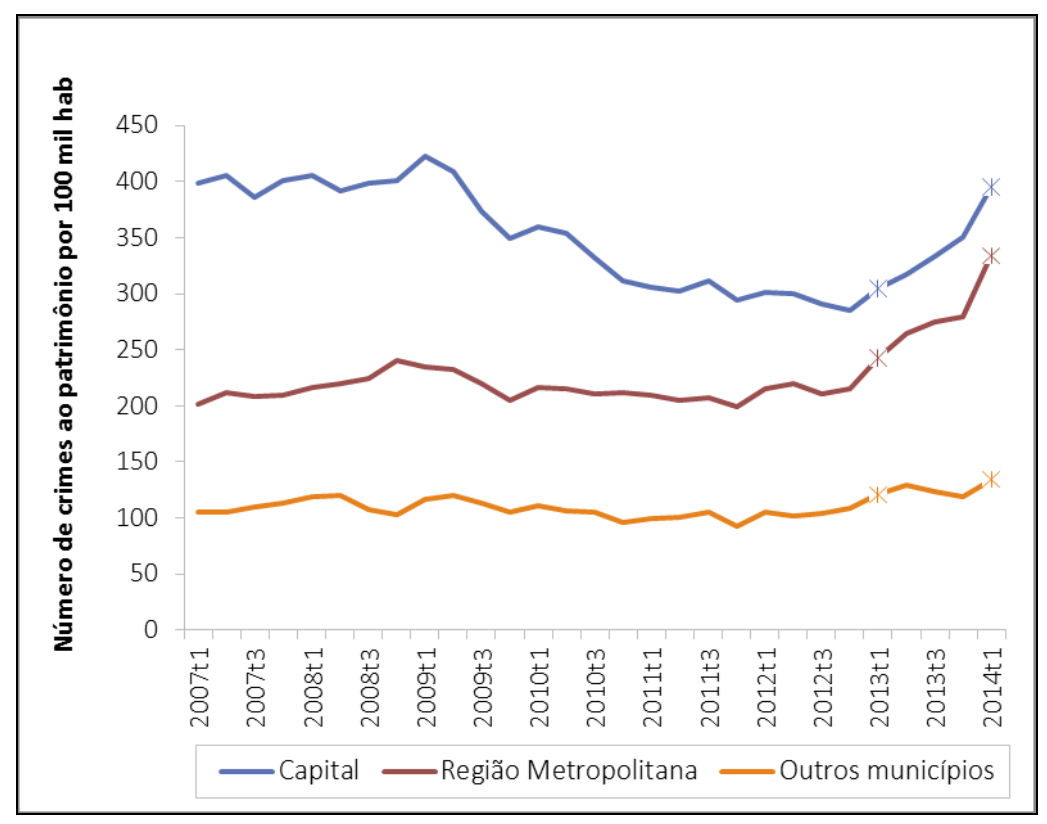

Fonte: Elaboração própria baseada em dados da SESEG.

Segundo o G1 Online (2014) a violência em Niterói e São Gonçalo tem aumentado. Segundo dados do Instituto de Segurança Pública (ISP), o número de roubos na região cresceu quase 40\% nos meses de abril e maio de 2014 em comparação ao mesmo período de 2013. De acordo com o levantamento, o número de homicídios dolosos - quando há intenção de matar aumentou $20 \%{ }^{6}$.

Segundo o Estadão Online (2014) os dados divulgados pelo Instituto de Segurança Pública da criminalidade no primeiro trimestre de 2014, demonstram que a violência no Rio voltou aos níveis do mesmo período do ano de 2008, antes da implementação das Unidades de Policia Pacificadora - UPP que teve início em dezembro do mesmo ano no Morro Dona Marta em Botafogo na Zona sul da cidade do Rio de Janeiro.

O índice de criminalidade divulgado pelo Instituto de Segurança Pública mostrou que 1.459 (mil quatrocentos e cinquenta e nove) pessoas foram assassinadas no primeiro trimestre de 2014. Bem próximo do número de 1.562 (mil quinhentos e sessenta e dois) registrados em 2008. Em 2012, ano que houve menor índice de homicídios (4.030, no total), o primeiro trimestre teve 1.100 (mil e cem) casos. Depois das Instalações das UPPs, o índice de ocorrências vinha demonstrando declínio. Houve 358 (trezentos e cinquenta e oito) autos de resistência ${ }^{7}$ (morte em confronto com a polícia) registrados no primeiro trimestre de 2008. Esse número caiu para 111 
(cento e onze) em 2012 e 96 (noventa e seis) em 2013. Em 2014 voltou a subir chegando a 153 (cento e cinquenta e três) $^{8}$. Os roubos de veículos haviam caído de 7.359 (sete mil trezentos e cinquenta e nove) nos três primeiros meses de 2008, para 5.598 (cinco mil quinhentos e noventa e oito) em 2012. No primeiro trimestre de 2014 ultrapassou a marca pré-UPP onde foram registrados 9.209 (nove mil duzentos e nove).

Os roubos de rua (índice que reúne número de assaltos a transeuntes, roubo de celular e em transporte público) também voltaram a subir. Houve 20.648 (vinte mil seiscentos e quarenta e oito) casos de janeiro a março de 2008. Em 2012, houve 15.422 (quinze mil quatrocentos e vinte e dois) casos no período. Em 2014 foram registrados 23.675 (vinte e três mil seiscentos e setenta e cinco) casos.

Em contrapartida, numa busca categórica de blindagem do modelo de política de (in) segurança pública materializados nas UPPs, e o seu não enfado fracasso a página eletrônica das UPPs divulga “Índice de criminalidade reduz com UPPs nos últimos seis anos”, índices estes contraditórios com a realidade e com dados apresentados anteriormente.

Segundo a coordenação das Unidades de Polícia Pacificadoras - UPP:

Desde a criação das Unidades de Polícia Pacificadora (UPPs), os índices de criminalidade apresentam melhoras expressivas nas áreas atendidas com policiamento de proximidade. Os últimos números foram divulgados no dia 9 de dezembro e mostram uma queda de $80,7 \%$ na letalidade violenta, que envolve crimes de homicídio doloso, latrocínio, homicídio decorrente de intervenção policial e lesão corporal seguida de morte. (2014)

Os indicadores divulgados pelo Instituto de Segurança Pública (ISP) referem-se à comparação do primeiro semestre de 2008 (ano de instalação da primeira UPP) com o primeiro semestre de 2014. Os números dizem respeito a 33 Unidades de Polícia Pacificadora. Homicídios dolosos analisados reduziram em 65,5\%. A diminuição dos autos de resistência (mortes em operações policiais) ${ }^{9}$ também ajuda a mensurar como mudou a relação entre polícia e moradores de comunidades após a pacificação. Esse tipo de ocorrência caiu 90,72\% no período analisado. Por outro lado, a apreensão de drogas cresceu $264,4 \%$ no mesmo intervalo. O levantamento aponta ainda redução nos roubos de rua $(59,8 \%)$, nas armas apreendidas $(78,2 \%)$ e nas ocorrências com flagrantes $(246,2 \%)(2014)$. 


\section{Figura 3.}

\section{REDUÇÃO DOS ÍNDICES DE CRIMINALIDADE ENTRE 2008 E 2014}

HOMICIDIO DOLOSO LETALIDADE VIOLENTA ROUBO DE RUA APREENSÃO DE DROGAS AUTOS DE RESISTÊNCIA $\downarrow 65,5 \%$

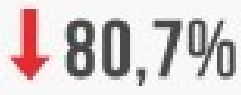

$59,8 \%$

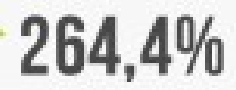

$\downarrow 90,72 \%$

Fonte: Instituto de Segurança Pública

De acordo com a coordenação das Unidades de Polícia Pacificadora foram analisadas as UPPs: Adeus/Baiana, Alemão, Andaraí, Barreira do Vasco/Tuiuti, Batam, Borel, Caju, Cidade de Deus, Cerro-Corá, Chapéu-Mangueira/Babilônia, Chatuba, Coroa/Fallet/Fogueteiro, Escondidinho/Prazeres, Fazendinha, Fé/Sereno, Formiga, Jacarezinho, Macacos, Mangueira, Manguinhos, Nova Brasília, Parque Proletário, Pavão-Pavãozinho, Providência, Rocinha, Salgueiro, Santa Marta, São Carlos, São João/Quieto/Matriz, Tabajaras, Turano, Vidigal e Vila Cruzeiro. (UPP, 2014)

Neste sentido, nossa idéia de migração e expansão da criminalidade através do processo de deslocamento para outras áreas após a territorialização das UPPs torna-se cada vez mais materializadas devido ao aumento dos índices de criminalidade no Estado.

Deste modo, não podemos deixar de ressaltar mais uma vez a questão do projeto de cidade (FREIXO, 2011) materializado nas ações geoestratégicas do modelo de UPPs com suas intervenções seletivas que objetivam não sua implementação em áreas com índices mais violentos, conforme demonstrado nos dados anteriores, mas sim na estruturação do cinturão de (in) segurança pública. 


\section{Mapa 1}

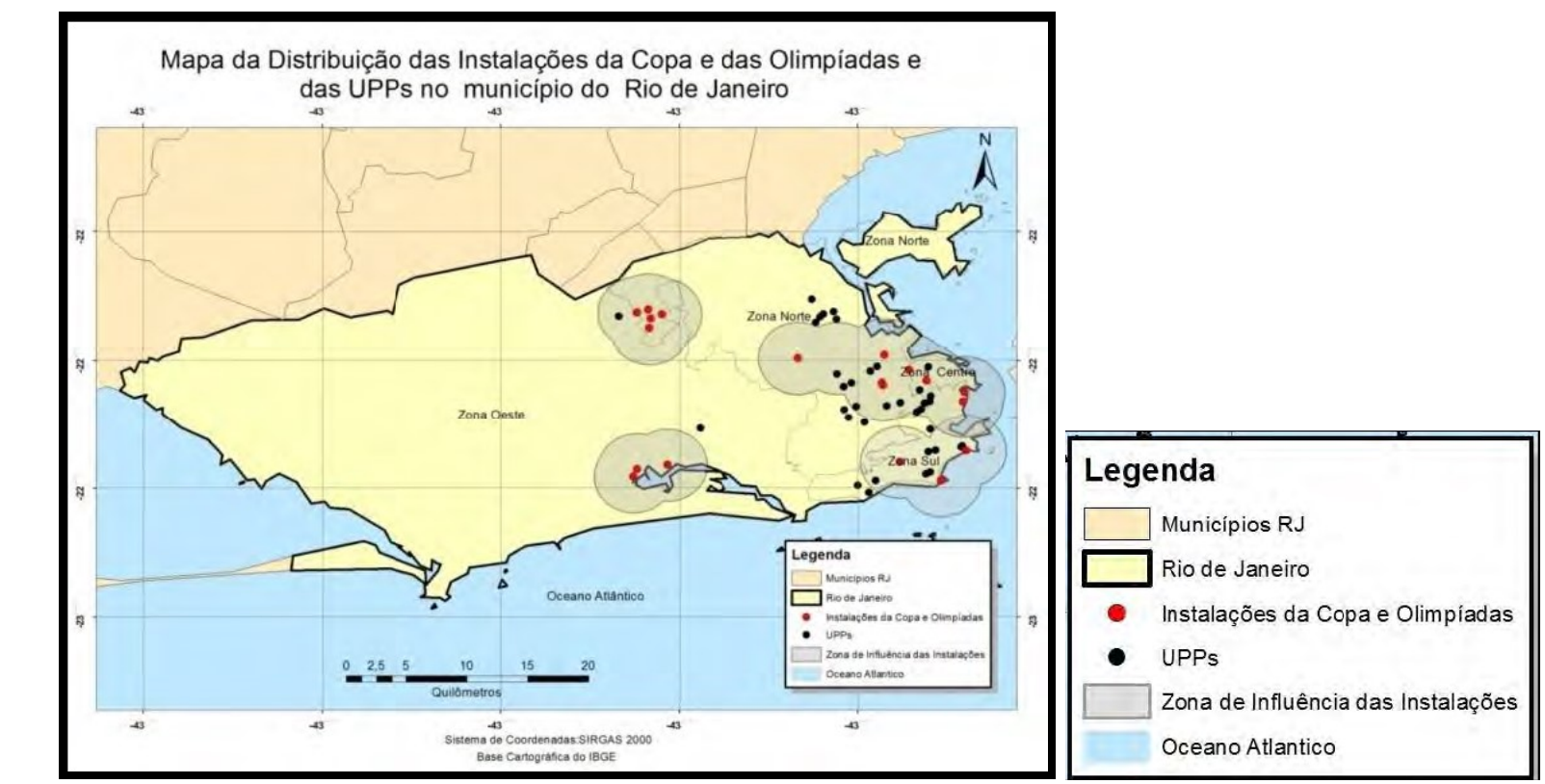

Fonte:(FERNANDES JUNIOR, 2012)

A distribuição geográfica das ocupações e instalações das UPPs nos traz uma visão nítida da estratégia das políticas de (in) segurança, claramente direcionada para garantir a sensação de segurança para determinadas áreas da cidade (Centro, Tijuca, Zona Sul, Barra da Tijuca), consequentemente a violência urbana se expande num processo de metropolização devido a tais intervenções seletivas. Neste sentido, as ações seletivas priorizam não apenas as áreas mais ricas da cidade, mas também aos novos empreendimentos imobiliários, turísticos e esportivos relacionados aos megaeventos.

Esta ideia estaria vinculada a intervenções seletivas e pontuais das UPPs, fortalecendo a lógica de um projeto de cidade, que não abrangendo a todo o Estado. Por este motivo, alguns grupos de narcotraficantes e milícias, não são combatidos por este modelo, por estarem fora do contexto das áreas de intervenção e de grande investimento do capital, fortalecendo assim a ideia de fragmentação do tecido sócio-pólitico (SOUZA, 2000) e de segregação espacial.

Articulamos a espacialização do modelo, materializadas nas ações táticas (curto e médio prazo) das UPPs relacionadas com as instalações da Copa do Mundo, Olimpíadas e Porto Maravilha na visualização das ações estratégicas (longo prazo) fortalecidas na ideia da questão do projeto de formação do cinturão da (in) segurança pública entorno do Maracanã (FERNANDES JUNIOR, 2012). 


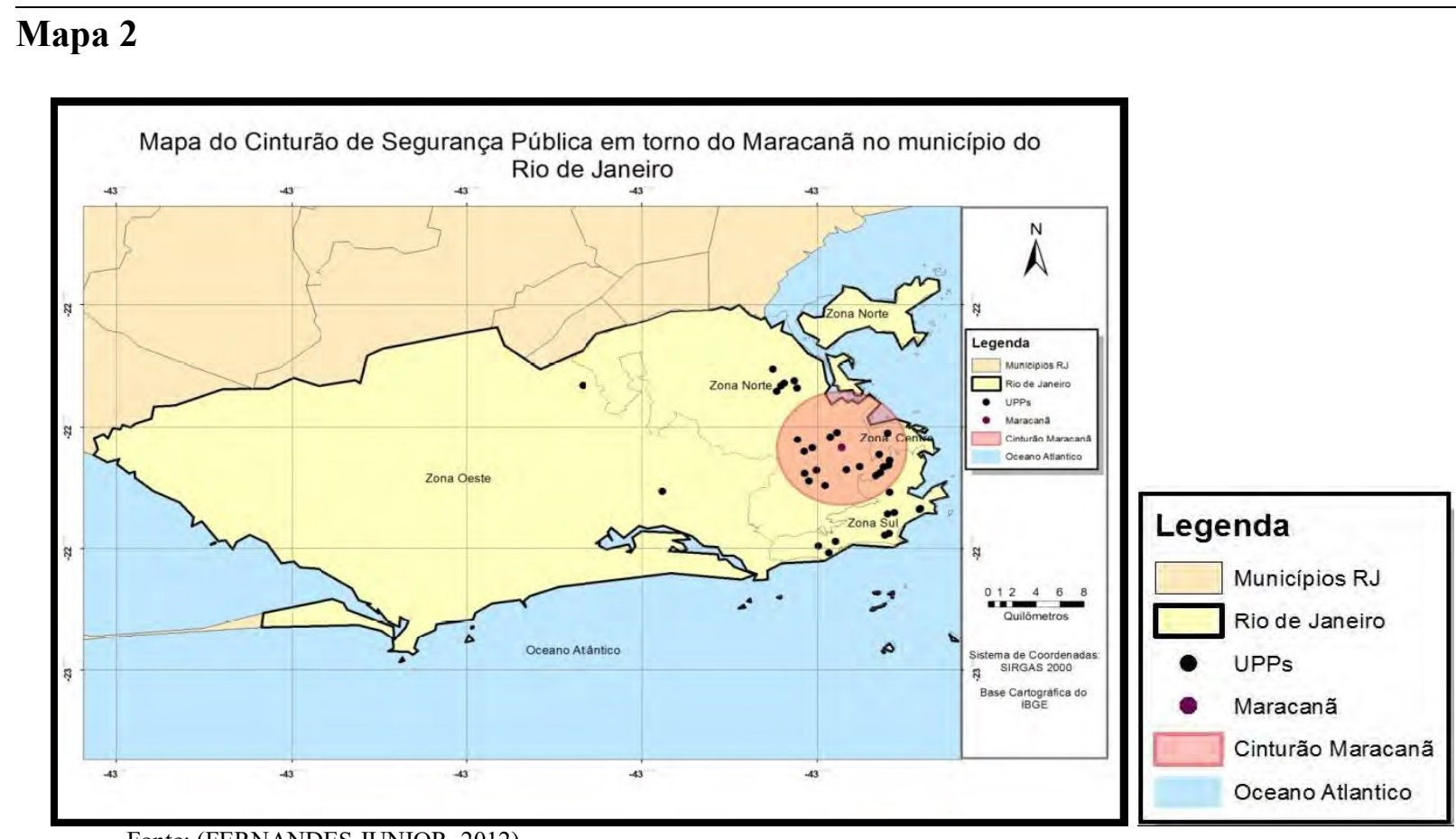

Fonte: (FERNANDES JUNIOR, 2012).

O processo de deslocamento da criminalidade, segue um desdobramento lógico, onde os criminosos migram das áreas territorializadas pela implementação das UPPs para as regiões mais próximas comandadas pela mesma facção e até mesmo ultrapassam este nível de abrangência numa escala de metropolização da criminalidade.

Baseado nos dados discutidos e impulsionado pela territorialização das UPPs relacionadas ao deslocamento dos grupos de narcotraficantes, entendemos como necessário a formulação de um mapeamento destas migrações em escala do Município do Rio de Janeiro externando para o nosso objetivo neste momento de materializar a metropolização da criminalidade. 


\section{Mapa 3}

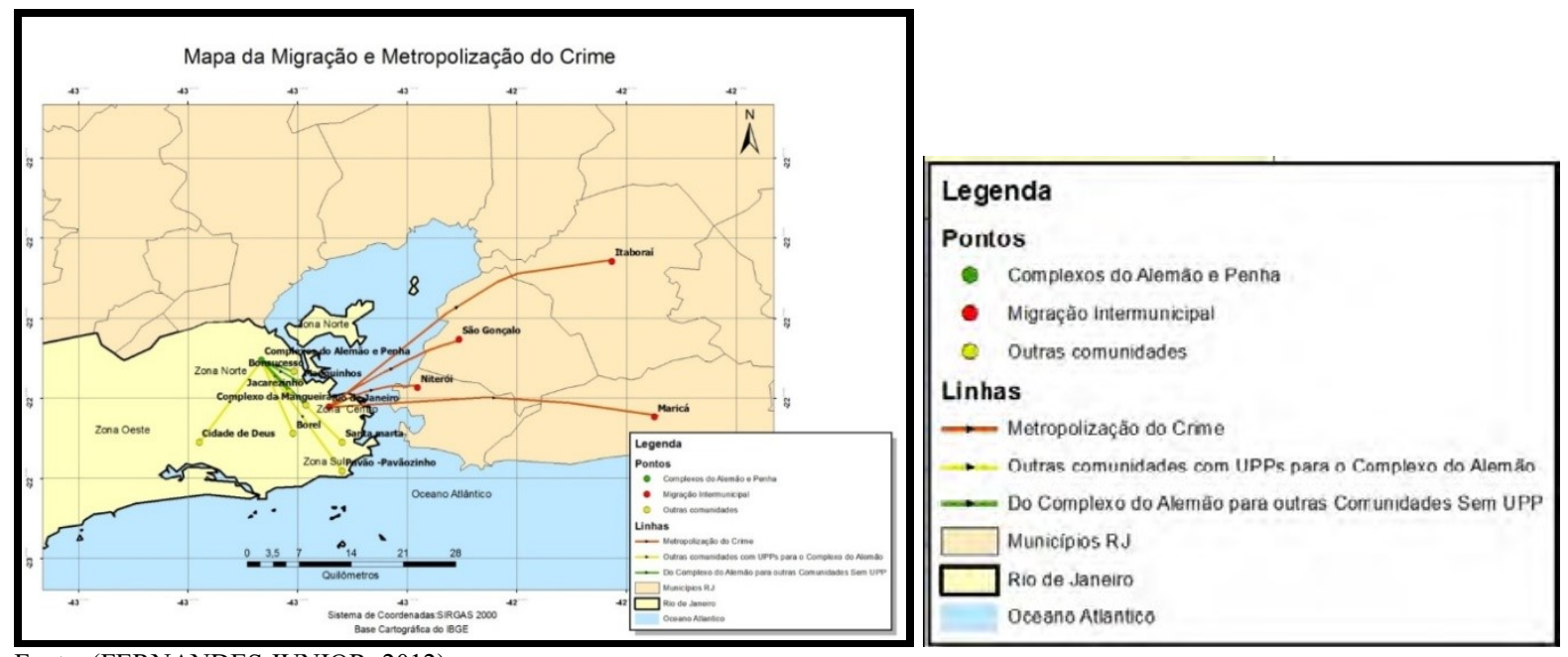

Fonte: (FERNANDES JUNIOR, 2012).

Neste sentido, processo de deslocamento da criminalidade, devido a territorialização nas áreas conflagradas pelo tráfico de drogas pela implementação das UPPs, nos conduzem a novas conjunturas em relação a este processo, no que diz respeito às migrações. Mas para compreendermos tais reflexões devemos apontar algumas ideias para contextualizar.

A primeira delas seria a própria implementação, onde grandes áreas de conflitos precisariam ser ocupadas, requerendo a um grande número de efetivo policial. Sendo assim, esta medida ocasionou um segundo problema, a defasagem do efetivo dos batalhões com a metropolização e migração da criminalidade, devido aos novos policiais recém-formados serem enviados diretamente para as UPPs, não repondo o lugar dos policias que estão em situação de Licença, doença e aposentadoria.

Como aponta o DECRETO $\mathrm{n}^{\mathrm{o}} 42.787$ de 06 de janeiro de 2011 que dispões sobre a implementação, estrutura, atuação e funcionamento das Unidades de Polícia Pacificadoras (UPPs):

Art. $5^{\circ}$ - As UPP serão classificadas de acordo com o efetivo de policiais previsto para a sua área de atuação e terão estrutura compatível para o exercício de suas atribuições.

$\S 1^{\circ}$ - A classificação das UPP se dará da seguinte forma:

I - As UPP serão classificadas como classe "A", quando o seu efetivo previsto for superior a 400 (quatrocentos) policiais militares.

II - As UPP serão classificadas como de classe "B" quando o seu efetivo previsto for no máximo de 400 (quatrocentos) policiais militares.

$\S 2^{\circ}$ - O efetivo mínimo previsto de uma UPP não poderá ser inferior a $100(\mathrm{cem})$ policiais militares, salvo em condições especiais julgadas pelo Secretário de Estado de Segurança. 
Art. $6^{\circ}-\S 2^{\circ}$ - Os policiais militares classificados nas unidades de polícia pacificadora deverão ter formação especial, com ênfase em Direitos Humanos e na doutrina de Polícia Comunitária, e os soldados deverão, "obrigatoriamente, ser policiais militares recémformados”. (DIÁRIO OFICIAL DO ESTADO DO RIO DE JANEIRO, 2011)

Desta maneira, as áreas dos batalhões com pouco efetivo, não conseguem diminuir os índices de criminalidade com o processo de migração, ao mesmo tempo, que as áreas de UPPs começam a dar sinais do reinicio da "estética do poder" por grupos de narcotraficantes (FERNANDES JUNIOR, 2012).

$\mathrm{Na}$ tentativa de melhor exemplificação de nossa ideia, as análises apresentadas nos gráficos 3 e 4 tiveram como base comparações entre os anos de 2008 `a 2014, tomando-se como referência de análise o ano de implementação do Projeto de Unidade de Polícia Pacificadora em 2008. No entanto, para uma reflexão mais aprofundada da evolução das incidências criminais, utilizamos índices.de policiais mortos e feridos em áreas de UPPs e índices de ocorrências criminais no restante do Estado do Rio de Janeiro.

Neste sentido, a partir do ano 2012, os índices de violência começam a subir em áreas de UPPs onde os conflitos armados retornaram junto com a "estética de poder", registrado as primeiras cinco mortes de policiais em áreas de UPPs; em 2013 foram 03 (três); em 2014, o número de policiais mortos em serviço em áreas de UPPs chegaram a 08 (oito); em 2015, foram 07 (sete) até julho. O número de policiais feridos em áreas de UPPs incluindo operações, patrulhamentos ou ataques às sedes e pontos fixos: foram 01 (um) em 2010, 05 (cinco) em 2011, 09 (nove) em 2012, 24 (vinte e quatro) em 2013, 87 (oitenta e sete) policiais feridos em 2014. Em 2015, até julho, foram 54 (cinquenta e quatro) policiais, conforme aponta o gráfico 3. 


\section{Gráfico 3 - Policiais mortos e feridos por disparos de arma de fogo em áreas de UPPs.}

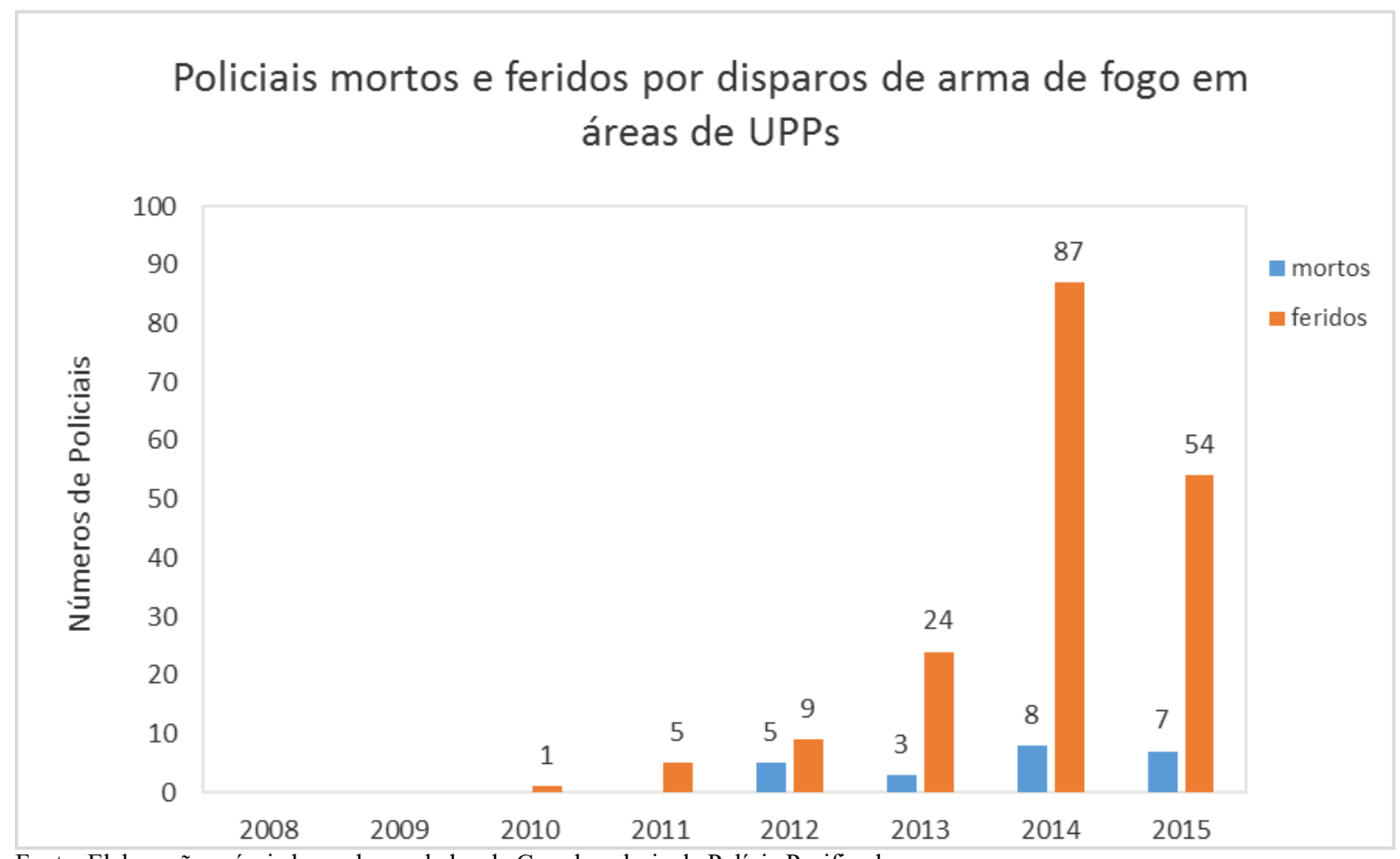

Fonte: Elaboração própria baseada em dados da Coordenadoria de Polícia Pacificadora.

As ocorrências criminais no Estado do Rio de Janeiro reduziram seus índices entre os anos de 2008 a 2011. A partir de 2012 voltaram a aumentar (BALANÇO ANUAL, 2014), devido ao processo de migração e expansão dos grupos de narcotraficantes. Conforme gráfico 4. 


\section{Gráfico 4 - Ocorrências criminais no Estado do Rio de Janeiro entre 2008 e 2014.}

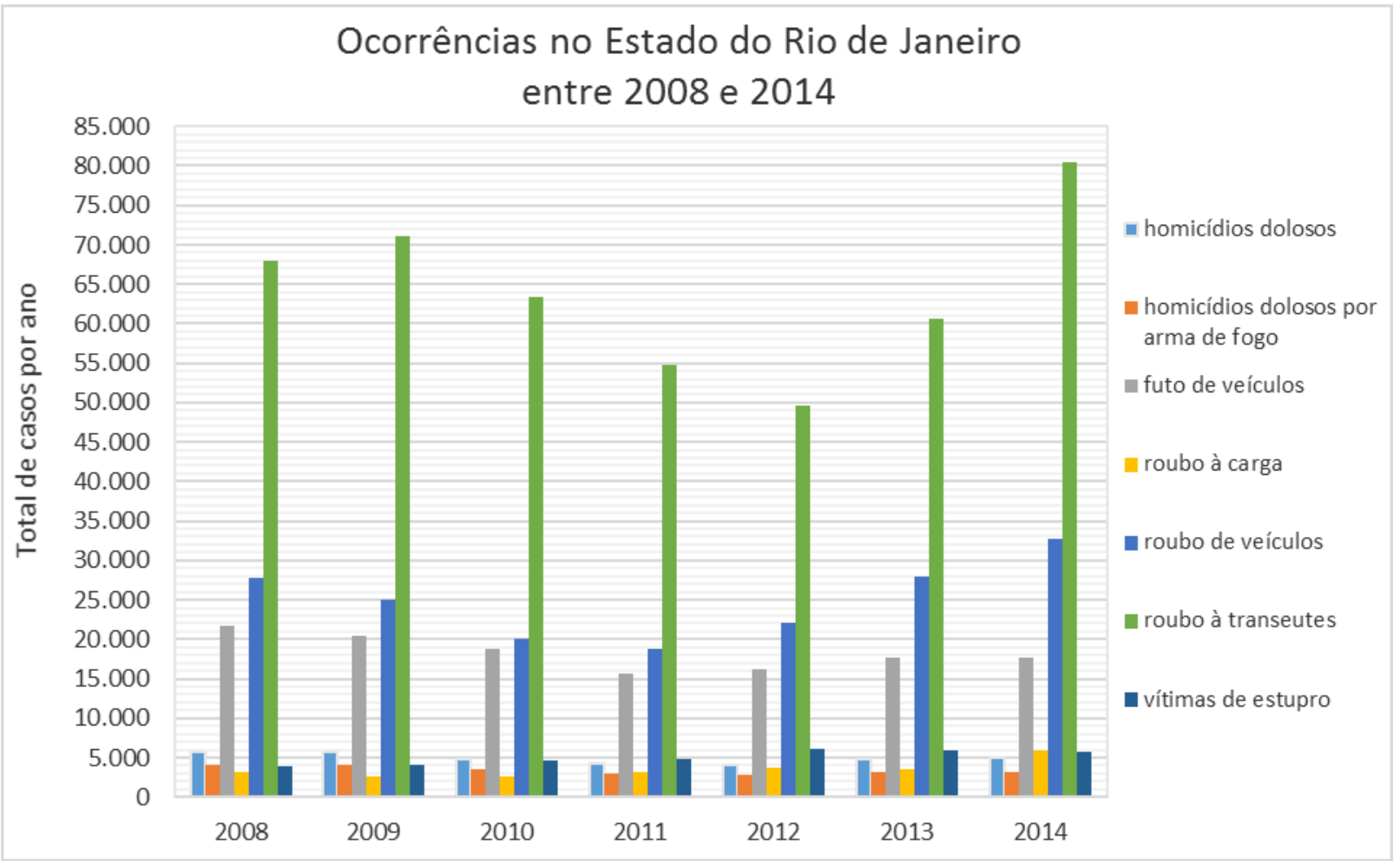

Fonte: Elaboração própria baseada em dados do DGTIT/PCERJ/ISP.

Esta problemática ocorre devido ao que chamaremos de medida do "cobertor curto", onde a política de (in) segurança teve que diminuir o envio de efetivos para as UPPs e enviar para os batalhões na tentativa de diminuição dos índices de criminalidade.

Desta forma, podemos direcionar a uma nova problemática: a expansão da criminalidade devido a territorialização das UPPs e a migração da criminalidade, externadas das áreas de UPPs para áreas dos batalhões. Tal fato se dá devido ao aumento da "estética de poder" nestas áreas com pouca expressão e representação no trafico de drogas, onde o ingresso no trafico de drogas de pessoas locais se torna cada vez maior nas áreas dos batalhões.

Fato este demostrado no gráfico 5 com o aumento dos confrontos armados entre policias e narcotraficantes nos chamados 'autos de resistências' ou homicídios em decorrência de intervenção policial. 


\section{Gráfico 5 - Homicídios decorrentes de intervenção policial no Rio de Janeiro.}

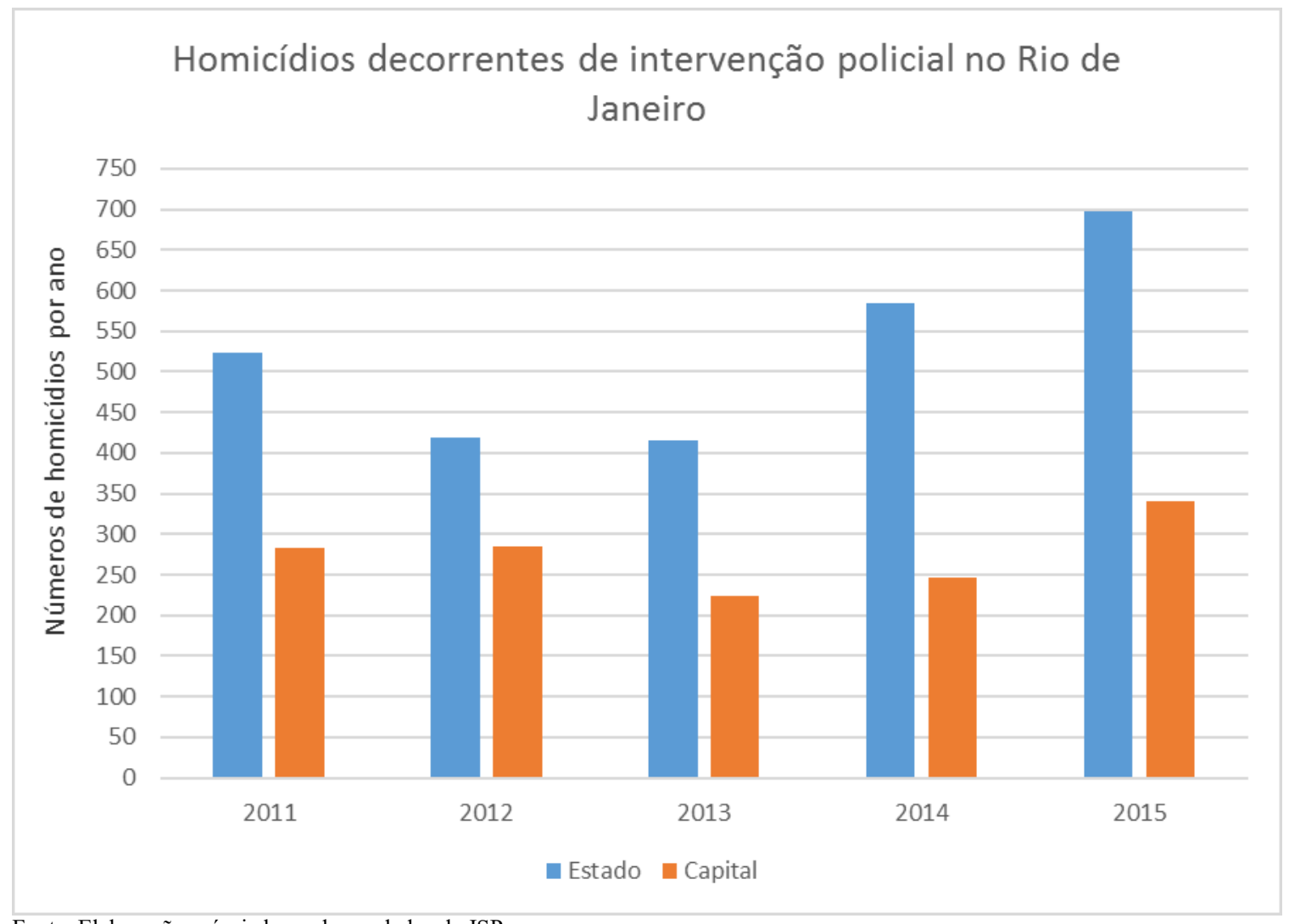

Fonte: Elaboração própria baseada em dados do ISP.

\section{CONSIDERAÇÕES FINAIS}

Neste sentido, o modelo de intervenção seletivo e pontual inserido no espaço urbano carioca pelo poder público através da (in) segurança pública, tem apontado uma vertente contraditória, no que diz respeito à diminuição da criminalidade, revertendo numa dinâmica de migração e de expansão territorial dos grupos de narcotraficantes e milicianos, onde as Unidade de Policia Pacificadora - UPP tem remetido um papel inverso do que se foi proposto inicialmente como agente mediador de conflitos. Porém, com o decorrer do tempo surgem questionamentos sobre a eficácia deste modelo, apontando num sentido completamente diferente. Segundo elementos iniciais das nossas pesquisas, as Unidades de Polícia Pacificadoras - UPPs estão passando de agente mediador para agente causador/gerador de conflitos devido a territorialização das UPPs. Tais idéias se materializam devido à expansão do trafico de drogas e expansão das milícias (em projetos como minha casa minha vida), além da migração de drogas (aumento dos pontos de venda), armas e de migração e nomeação de lideranças do narcotráfico em áreas de 
expansão, onde a 'estética do poder" (FERNANDES JUNIOR, 2012) ressurge em áreas de UPPs e se implementa em áreas de expansão como difusor e receptor da violência.

Assim, o ressurgimento da "estética do poder" em áreas de UPPs (Idem) emergem onde suas bases não demarcam posições nos morros, mas sim pontos estratégicos de um perímetro da região ou área total. Este fato está relacionado a falta de efetivo para ocupar toda área; o difícil acesso (relacionado ao relevo ou ao intenso conflito armado de determinadas áreas conflagradas que dificultam a permanência). Este perímetro cada vez mais está diminuindo, devido à migração e expansão dos grupos de narcotraficantes e o ressurgimento da "estética do poder", onde estas áreas tornam-se cada vez mais conflagradas. Desta forma, para onde caminhará este modelo? As UPPs tornam-se um agente causador/ gerador de conflitos? As UPPs têm gerado processos de precarização territorial com a migração/expansão da criminalidade para novas áreas? $\mathrm{O}$ ressurgimento da "estética do poder" como apontado em trabalho anterior (FERNANDES JUNIOR, 2012) nas novas áreas dominadas pela criminalidade tem promovido restrições e contenções territoriais no uso e apropriação dos espaços dos moradores destas áreas? Algumas respostas já foram apontadas, mas a implementação de uma política de (in) segurança pública seletiva e pontual sem planejamento pode ser um dos motivos para tantos problemas, no entanto ainda há uma necessidade de mais estudos e uma agenda de investigação dessa política pública.

\section{NOTAS}

1. A utilização do termo (in) segurança pública foi inspirada no autor Rogério Haesbaert para ressaltar que as chamadas políticas de segurança, vem gerado mais insegurança do que segurança, ou seja, as políticas de segurança pública não têm conseguido impedir a violação dos direitos básicos, esta violação geralmente vem acompanhada de violência que produz eventos de insegurança e criminalidade. Por este motivo o termo é colocado entre parênteses.

2. Para um melhor entendimento sobre o conceito de geoestratégia ressaltaremos mesmo que sucinta uma distinção entre estratégia e geoestratégia. A estratégia possui uma dimensão não espacial (quem e como vai comandar uma tropa, por exemplo, ou como se dará a renovação tecnológica do armamento) ou uma parte ou dimensão espacial (onde vai ficar posicionada tal tropa, para onde ela vai se deslocar etc.). Esta dimensão espacial é a geoestratégia, ou seja, localização e distribuição. Ver Cf. WACKERMANN, Gabriel. Géopolitique de l'espace mondial. Paris: Ellipses, 1997, p.5.

3. Esta é a marca da inscrição espacial do neoliberalismo que deixa de ver a cidade como um todo. 
4. O termo 'milícias' começou a ser usado de forma frequente no ano de 2006 por órgãos de imprensa e representantes públicos para designar um fenômeno que se expandia rapidamente naquele momento. Esses grupos foram comparados à chamada "polícia mineira", que se constituiu na década de 1980, a partir da Zona Oeste. Ver BURGOS, Marcelo (Org.) A utopia da Comunidade: Rio das Pedras, uma favela carioca. Rio de Janeiro: PUC-Rio: Loyola, 2002.

5. Crimes ao patrimônio incluem roubos ao comércio, residência, veículo, carga, transeunte, banco, caixa eletrônico, roubo em coletivo, roubo com condução a saque, furto de veículos, sequestro, extorsão, sequestro relâmpago e estelionato.

6. Lembremos que este período era da véspera da Copa do Mundo do Brasil que tinha a cidade do Rio de Janeiro como um dos principais palcos do marketing urbano para atração de turistas e investimentos internacionais.

7. O auto de resistência é uma medida administrativa criada durante a Ditadura Militar para legitimar o conflito armado seguido de morte entre as forças policiais e 'bandidos'.

8. Esse dado tem sido apontado por movimentos sociais como uma das marcas históricas do autoritarismo da polícia e a gestão biopolítica do espaço (OLIVEIRA, 2014). O conceito de biopolítica (FOUCAULT, 2008) utilizado por (OLIVEIRA, 2014) é baseado em uma das cinco categorias do autor Michael Foucault, chamada biossegurança (FOUCAULT, 1985) que é associada aqui a ideia de segurança e os mecanismos de controle seletivos.

9. No entanto, ao contrário das informações do Instituto de Segurança Pública (ISP) os autos de resistência na atual política de (in) segurança não altera em nada o modus operandi das forças policiais tão criticados por sua violência. Deste modo tramita no Congresso Nacional o Projeto de Lei $\mathrm{n}^{0}$ 4471/2012, que tem como objetivo regulamentar a investigação criminal em operações policiais que resultam em morte. A ideia é acabar com o uso indiscriminado de termos como 'resistência seguida de morte' e 'autos de resistência' em registros de ocorrências policiais em casos de lesão corporal grave, morte ou qualquer dano a qualquer direito.

\section{REFERÊNCIAS}

BALANÇO ANUAL, Balanço das Incidências Criminais e Administrativas no Estado do Rio de Janeiro (2014). Instituto de Segurança Pública, 2014.

CORREA, Roberto Lobato. Corporação, Práticas Espaciais e Gestão do Território. Revista Brasileira de Geografia, Rio de Janeiro, 5 (3): 115-121, 1992.

DIÁRIO OFICIAL DO ESTADO DO RIO DE JANEIRO, Poder Executivo, Ano XXXVII, $\mathrm{N}^{\circ} 005$, Parte I de 07 de janeiro de 2011.

ESTADÃO Online. Disponível em: <http://www.estadao.com.br/noticias/geral,violencia-no-riode-janeiro-retoma-niveis-pre-upps,1161837> Acesso em 03 de maio de 2014.

FERNANDES JUNIOR, Graciano Lourenço. Unidade de Polícia Pacificadora (UPP) na era dos Mega Eventos: Algumas reflexões sobre a política de segurança pública na cidade do Rio de Janeiro, pós Pan-Americano de 2007. São Gonçalo, 2012.131 f. Dissertação (Especialização em 
Dinâmicas Urbano-Ambientais e Gestão do Território) Universidade do Estado do Rio de Janeiro - UERJ-FFP, São Gonçalo, 2012.

FREIXO, Marcelo. Nada deve ser impossível de mudar. Direitos Humanos no Brasil 2011Relatório da Rede Social de Justiça e Direitos Humanos. Rio de Janeiro, Expressão Popular, 2011.

FOUCAULT, M. 2008. Segurança, Território e População. São Paulo: Martins Fontes.

FOUCAULT, M. 1985. Direito de morte e poder sobre a vida. In: História da Sexualidade I: A vontade de saber. Rio de Janeiro: Graal.

G1 Online. Bandidos migram de comunidades pacificadas e assalto violento explode em Região Metropolitana do Rio. Disponível em: $<$ http://g1.globo.com/bom-diabrasil/noticia/2012/04/bandidos-migram-de-comunidades-pacificadas-e-assalto-violento-explodeem-regiao-metropolitana-do-rio.html>. Acesso em: 20 de abril de 2012.

G1 Online. PM quer criar cinturão de segurança contra violência na região de Niterói. Disponível em: < http://g1.globo.com/rio-de-janeiro/noticia/2012/04/pm-quer-criar-cinturao-de-segurancacontra-violencia-na-regiao-de-niteroi.html > Acesso em: 15 de abril de 2012.

G1 Online. Niterói e São Gonçalo têm aumento na violência, mostram dados do ISP. Disponível em: <http:/g1.globo.com/rio-de-janeiro/noticia/2014/07/niteroi-e-sao-goncalo-tem-aumento-naviolencia-mostram-dados-do-isp.html> Acesso em: 03 de julho de 2014.

GENEVA DECLARATION SECRETARIAT, 2011. Global Burden of Armed Violence.2011: Lethal Encounters. Cambridge: Cambridge University Press.

HAESBAERT, Rogério. O mito da desterritorialização: do "fim dos territórios" à multiterritorial idade. $3^{\mathrm{a}}$ ed. Rio de Janeiro: Bertrand, 2007.

HAESBAERT, Rogério.Territórios, in-segurança e risco em tempos de contenção territorial. Publicado em Póvoa Neto, H., Ferreira, A. Vainer, C., Santos M. (org.) A experiência migrante: entre deslocamentos e reconstruções. Rio de Janeiro: Garamond. 2010., p. 537-557.

OLIVEIRA, de Araújo Denílson. O marketing urbano e a questão racial na era dos megaempreendimentos e eventos no Rio de janeiro. Revista brasileira de estudos urbanos e regionais. V.16, $\mathrm{n}^{\circ} 1,2014$.

R7 Online. Ocupação do Alemão e da Penha provoca migração de crimes para outras áreas da cidade, aponta ISP. Disponível em: <http://noticias.r7.com/rio-de-janeiro/noticias/ocupacao-doalemao-e-da-penha-provoca-migracao-de-crimes-para-outras-areas-da-cidade-aponta-isp20110524.html >Acesso em: 20 de março de 2012.

SOUZA, M. L. Da "fragmentação do tecido sociopolítico-espacial" da metrópole à "desmetropolização relativa" algumas facetas da urbanização brasileira nas décadas de 80 e 90. Congresso anual da ADLAF, 1998. 
SOUZA, M. L. O desafio metropolitano: um estudo sobre a problemática sócio-espacial nas metrópoles brasileiras. Rio de Janeiro: Bertrand Brasil, 2000.

TERRA Online. Vídeo mostra arsenal do tráfico no Rio de Janeiro. Disponível em:

$<$ http://noticias.terra.com.br/brasil/noticias/0,,OI4723701-EI5030,00 Video

+ mostra + arsenal + do + trafico + no + Rio + de + Janeiro.html $>$ Acesso em: 20 de março de 2012.

UOL Online. Criminalidade subiu no Rio em áreas de onde policiais foram deslocados para protestos, diz PM. Disponível em: <http:/noticias.uol.com.br/cotidiano/ultimasnoticias/2013/10/31/criminalidade-subiu-no-rio-em-areas-onde-policiais-foram-deslocados-paraprotestos-diz-pm.htm>Acesso em: 20 de novembro de 2013.

UNIDADE DE POLÍCIA PACIFICADORA. Índices de criminalidade reduzem com UPPs nos últimos seis anos. Disponível em :< http://www.upprj.com/index.php/acontece/aconteceselecionado/indices-de-criminalidade-reduzem-com-upps-nos-ultimos-seis-anos/CPP $>$. Acesso em: 20 de dezembro de 2014.

VESENTINI, José William. Novas geopolíticas. 5.ed. São Paulo: Contexto, 2001. 